\title{
Constitutive STAT3 Serine Phosphorylation Promotes Helicobacter-Mediated Gastric Disease
}

Jesse J. Balic, ${ }^{* \dagger}$ Mohamed I. Saad, ${ }^{* \dagger}$ Ruby Dawson, ${ }^{* \dagger}$ Alice J. West,${ }^{* \dagger}$ Louise McLeod, ${ }^{* \dagger}$ Alison C. West,,${ }^{* \dagger}$ Kimberley $\mathrm{D}^{\prime}$ Costa,,${ }^{* \dagger}$ Virginie Deswaerte, ${ }^{* \dagger}$ Anouk Dev, ${ }^{\ddagger}$ William Sievert, ${ }^{\ddagger}$ Daniel J. Gough, ${ }^{\dagger \S}$ Prithi S. Bhathal, ${ }^{\dagger}$ Richard L. Ferrero, ${ }^{* \uparrow}$ and Brendan J. Jenkins*广

From the Centre for Innate Immunity and Infectious Diseases* and the Centre for Cancer Research, ${ }^{\S}$ Hudson Institute of Medical Research, Clayton; the Department of Molecular Translational Science, ${ }^{\dagger}$ Faculty of Medicine, Nursing and Health Sciences, and the Department of Microbiology, ${ }^{\circledR}$ Biomedicine Discovery Institute, Monash University, Clayton; and the Department of Gastroenterology and Hepatology, ${ }^{\ddagger}$ Monash Health, Melbourne, Victoria, Australia

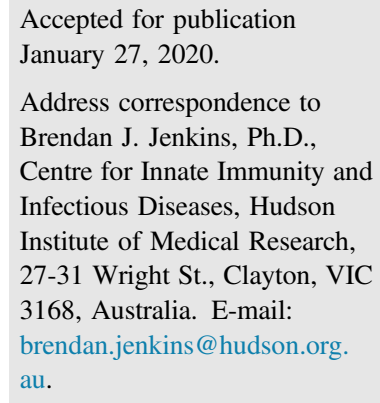

The pathogenesis of gastric cancer is strongly associated with chronic gastric inflammation (gastritis) caused by persistent Helicobacter pylori infection. ${ }^{1}$ Gastritis and the pathologic step-wise progression to gastric cancer, as described by using the Correa model, is triggered by a combination of host genetic polymorphisms governing the mucosal and immunologic responses to $H$. pylori colonization, the direct pathogenic effects of $H$. pylori virulence factors, and the overall interplay with environmental factors. ${ }^{2}$ Among the myriad of host immune response pathways previously implicated in $H$. pylori infection, the latent transcription factor STAT3 is a potent driver of numerous oncogenic cellular processes, including cell proliferation, survival and migration, inflammation, angiogenesis, and immunosuppression. ${ }^{3,4}$

\begin{abstract}
Gastric cancer is associated with chronic inflammation (gastritis) triggered by persistent Helicobacter pylori (H. pylori) infection. Elevated tyrosine phosphorylation of the latent transcription factor STAT3 is a feature of gastric cancer, including $H$. pylori-infected tissues, and aligns with nuclear transcriptional activity. However, the transcriptional role of STAT3 serine phosphorylation, which promotes STAT3-driven mitochondrial activities, is unclear. Here, by coupling serine-phosphorylated (pS)-STAT3-deficient Stat3 ${ }^{\text {SA/SA }}$ mice with chronic $H$. felis infection, which mimics human $H$. pylor in mice, we reveal a key role for pS-STAT3 in promoting Helicobacter-induced gastric pathology. Immunohistochemical staining for infiltrating immune cells and expression analyses of inflammatory genes revealed that gastritis was markedly suppressed in infected Stat3 ${ }^{\mathrm{SA} / \mathrm{SA}}$ mice compared with wild-type mice. Stomach weight and gastric mucosal thickness were also reduced in infected Stat3 ${ }^{\mathrm{SA} / S A}$ mice, which was associated with reduced proliferative potential of infected gastric mucosa. The suppressed $H$. felis-induced gastric phenotype of Stat3 ${ }^{\mathrm{SA} / \mathrm{SA}}$ mice was phenocopied upon genetic ablation of signaling by the cytokine IL-11, which promotes gastric on STAT3-regulated genes, rather than mitochondrial and metabolic genes. In the gastric mucosa of mice and patients with gastritis, pS-STAT3 was constitutively expressed irrespective of Helicobacter infection. Collectively, these findings suggest an obligate requirement for IL-11 signaling via constitutive pS-STAT3 in Helicobacter-induced gastric carcinogenesis. (Am J Pathol 2020, 190: 1256 -1270; https://doi.org/10.1016/j.ajpath.2020.01.021)
\end{abstract}

In response to Helicobacter infection, it has been largely assumed that STAT3 is activated in the gastric epithelium as a canonical, tyrosine-phosphorylated (pY) transcription factor, most likely via activation of tyrosine kinases such as

Supported by a National Health and Medical Research Council (NHMRC) of Australia research grant (B.J.J.), the Operational Infrastructure Support Program by the Victorian Government of Australia, an Australian Postgraduate Awards scholarship from the Australian Government (J.J.B.), a National Health and Medical Research Council (NHMRC) Early Career Fellowship (A.C.W.), an NHMRC Career Development Fellowship and a grant from the United States Department of Defense (D.J.G.), and NHMRC Senior Medical Research Fellowships (B.J.J. and R.L.F).

Disclosures: None declared. 
the Janus kinase (JAK) family. For instance, pY-STAT3 levels are elevated in gastric tissues from patients with $H$. pylori-positive gastritis, as well as in mouse and gerbil $H$. pylori infection models. ${ }^{4-6}$ Regarding these latter in vivo infection models, increased gastric epithelial pY-STAT3 levels are coincident with elevated mucosal inflammatory scores, and chronic infection of mice with the related $\mathrm{H}$. felis strain induces stromal and epithelial STAT3 tyrosine phosphorylation, which is associated with overall worse pathology scores. ${ }^{7}$ In the case of $H$. pylori, it has been shown that translocation of the virulence factor cytotoxinassociated gene A into gastric epithelial cells can augment STAT3 tyrosine phosphorylation via induction of upstream cytokine-receptor signaling circuits; the best documented of these is the gp130 signal-transducing receptor subunit for the IL-6 cytokine family (eg, IL-6, IL-11)., ${ }^{4,9}$

STAT3 activation can also be influenced by numerous posttranslational modifications, among which the serinephosphorylated $(\mathrm{pS})$ modification has attracted the most attention for its dual nuclear and mitochondrial activities. ${ }^{10}$ With respect to its canonical role in the nucleus, it was first suggested $>2$ decades ago that phosphorylation of STAT3 at the key serine 727 site (pS727) is necessary for maximal transcriptional output of STAT3-regulated genes, most likely by fostering STAT3 dimerization and DNA binding. ${ }^{11,12}$ However, the generation of pS-STAT3-deficient mice engineered with an alanine substitution at S727 $\left(\right.$ Stat $\left.^{\mathrm{SA} / \mathrm{SA}}\right)$ has yielded contrasting roles on the requirement of pS727 for the maximal transcriptional potential of STAT3, which may reflect context (eg, cell and tissue type) dependency. ${ }^{13,14}$ More recently, in particular for mutant Ras-addicted tumors, mitochondrial-localized pS-STAT3 can directly regulate the activity of the electron transport chain, and thus mitochondrial function and associated metabolic reprogramming of cancer cells, the latter a recently recognized hallmark of cancer. ${ }^{10,15-18}$

Despite evidence suggesting that pS727 modulates the oncogenic potential of STAT3, the role of STAT3 serine phosphorylation in Helicobacter-mediated gastric pathology is unknown. The current study shows that coupling Stat $3^{S A / S A}$ mice with a chronic $H$. felis infection model, which mimics preneoplastic changes in human disease, protects against gastritis, gastric mucosal hyperplasia, and intestinal metaplasia (IM). Notably, in contrast to Helicobacter-associated upregulation of pY-STAT3 in the gastric mucosa of infected mice and gastritis patient biopsy specimens, pS-STAT3 was constitutively expressed in gastric tissues irrespective of Helicobacter infection. The requirement by Helicobacter for pS-STAT3 coincided with the transcriptional activity on STAT3-regulated genes (eg, Ill1), rather than its effect on mitochondrial and metabolic gene networks. Furthermore, we show that the cytokine IL-11, which is up-regulated in gastric cancer and drives gastric tumorigenesis in a STAT3dependent manner, ${ }^{1-22}$ is also required for Helicobacterinduced gastric pathology. Collectively, these findings suggest a hitherto unknown pathogenic role for the IL-11-signaling axis and its obligate requirement for constitutive pS-STAT3 during Helicobacter-induced gastric disease.

\section{Materials and Methods}

\section{Human Biopsy Samples}

Gastric biopsy samples were collected from cancer-free individuals undergoing endoscopy, or from patients with gastric cancer (intestinal-type adenocarcinoma) undergoing surgical resection, at Monash Medical Center (Melbourne, Australia) (Supplemental Table S1). The biopsy samples were snap-frozen in liquid nitrogen or stored in $10 \%$ formalin, the latter for blinded histopathology (P.S.B.) on hematoxylin and eosin (H\&E)-stained sections using the updated Sydney system. ${ }^{23,24}$ H. pylori status was determined by using $16 S$ rRNA quantitative real-time PCR (qPCR) and assessment of Cresyl fast violet-stained tissue sections. ${ }^{24,25} H$. pylori-negative $\left(\mathrm{Hp}^{-}\right)$biopsy specimens without lesions were considered normal. Full and informed patient consent was obtained, and biopsy collections were approved by the Monash Health Human Research Ethics Committee.

\section{Mice}

Mice lacking either pS727 STAT3 $\left(\right.$ Stat $3^{\mathrm{SA} / \mathrm{SA}}$ ) or the IL-11 receptor $\left(\right.$ Ill1 $\mathrm{ral}^{-1-}$ ) have been described previously. ${ }^{13,26}$ Genetically matched (mixed 129Sv x C57BL/6) wild-type (WT) littermates were used as controls. Animals were housed under specific pathogen-free conditions, as defined by their negative status upon screening for 48 infectious agents by serology (eg, mouse rotavirus), parasitology (eg, helminths), PCR (eg, Helicobacter species, Mycoplasma), and bacteriology (eg, Escherichia coli, Enterobacter species). Experiments were approved by the Monash Medical Center B Animal Ethics Committee.

\section{Helicobacter Infection}

H. feli $^{27}$ suspensions were prepared by harvesting bacteria from horse blood agar plates using brain heart infusion broth. ${ }^{28}$ Mice were inoculated by oral gavage with a single $100 \mu \mathrm{L}$ aliquot of either control brain heart infusion or approximately $10^{7} \mathrm{H}$. felis bacteria. H. felis bacterial loads were confirmed by using qPCR amplification of the $\mathrm{H}$. felis flaB gene. ${ }^{29}$

\section{RNA Isolation and Gene Expression Analysis}

Total RNA was isolated from human and mouse gastric tissues by using TRI Reagent Solution (MilliporeSigma, Burlington, MA), followed by on-column RNeasy Mini Kit RNA clean-up and DNase treatment (Qiagen, Germantown, MD). cDNA was transcribed by using the Transcriptor High Fidelity cDNA Synthesis Kit (Roche, Basel, Switzerland). qPCR was performed on samples in technical triplicates 
Table 1 Primer Sequences Used for Quantitative Real-Time PCR Gene Expression Assays

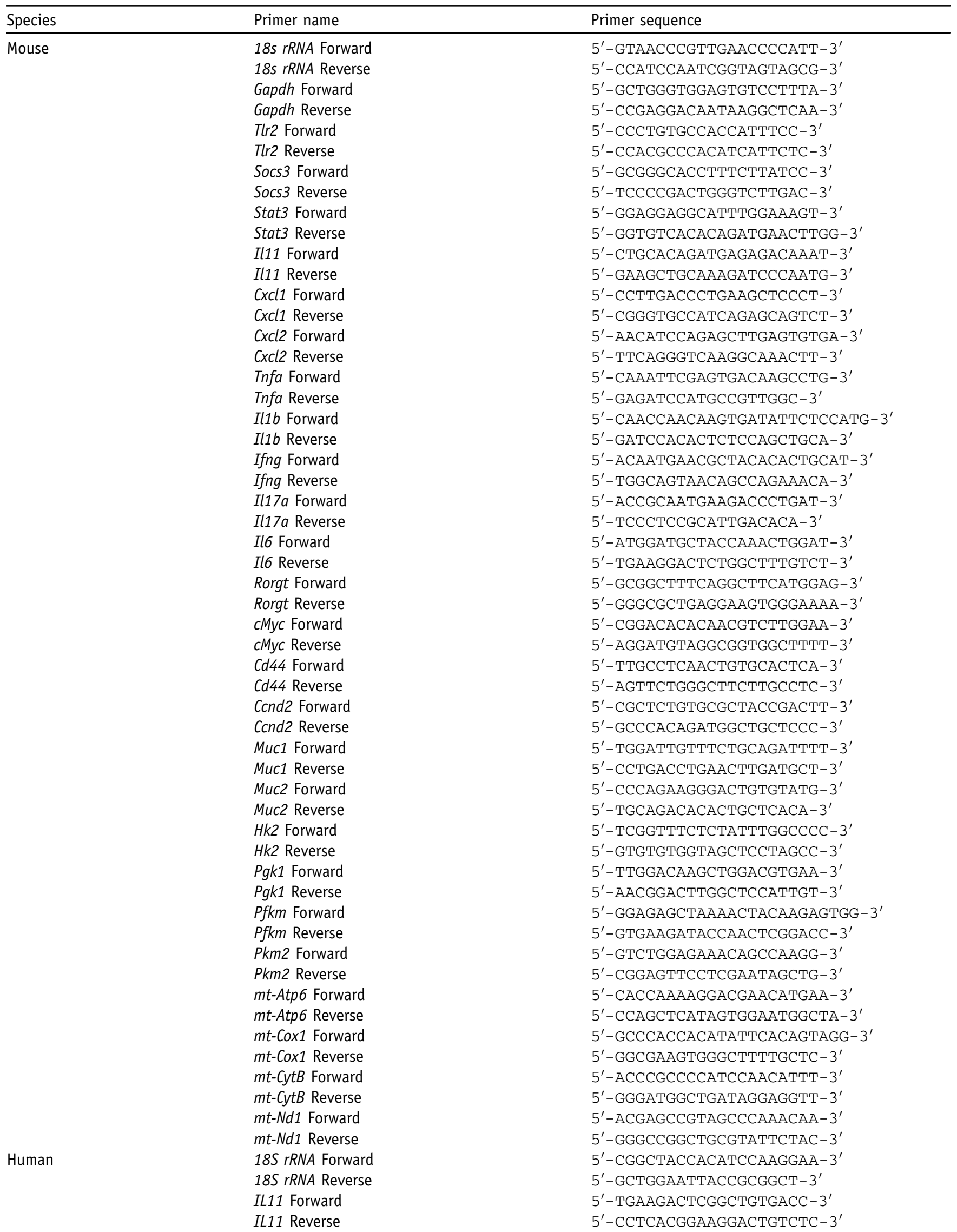

(table continues) 
Table 1 (continued)

\begin{tabular}{lll}
\hline Species & Primer name & Primer sequence \\
\hline H. felis & flaB Forward & $5^{\prime}-$ TTCGATTGGTCCTACAGGCTCAGA-3' $^{\prime}$ \\
& flaB Reverse & $5^{\prime}-$ TTCTTGTTGATGACATTGACCAACGCA-3' $^{\prime}$ \\
\hline
\end{tabular}

using the 7900HT Fast Real-Time PCR System (Thermo Fisher Scientific, Waltham, MA), and data acquired and analyzed as previously published. ${ }^{24}$ Mouse and human primer sequences are presented in Table 1.

\section{Immunoblot Protein Expression Analysis}

Antibodies against pY-STAT3 (\#9145; Cell Signaling Technology, Danvers, MA), pS-STAT3 (\#9134; Cell Signaling Technology), total STAT3 (\#9139; Cell Signaling Technology), and tubulin (\#ab6160; Abcam, Cambridge, United Kingdom) were used for immunoblotting. Membranes were scanned by using an Odyssey Infrared Imaging System (LI-COR) and quantified by using the LI-COR Odyssey Image Studio software version 3.0 (Odyssey, Lincoln, NE).

\section{Histology and Immunohistochemistry}

Whole mouse stomachs, along with human gastric biopsy specimens, were fixed overnight in $10 \%$ formalin and then washed/stored in $70 \%$ ethanol before paraffin embedding. Tissue sections (4 to $6 \mu \mathrm{m}$ ) were prepared for histologic assessment by H\&E staining, as well for Alcian blue/periodic acid-Schiff (PAS) staining, the latter with $1 \% \mathrm{w} / \mathrm{v}$ Alcian blue (3\% v/v acetic acid/distilled water, $\mathrm{pH} 2.5)$, followed by $1 \% \mathrm{v} / \mathrm{v}$ periodic acid/distilled water and then Schiff's reagent before hematoxylin counterstaining. For immunohistochemistry, after deparaffinizing in xylene and sequential rehydration, antigen retrieval was performed as follows: heated $1 \mathrm{mmol} / \mathrm{L}$ EDTA, pH 8.0 for pY-STAT3 (\#9145), and heated $10 \mathrm{mmol} / \mathrm{L}$ sodium citrate acid, $\mathrm{pH} 6.0$ for pS-STAT3 (\#sc-8001-R; Santa Cruz Biotechnology, Dallas, TX), PCNA (\#2586; Cell Signaling Technology), cMyc (\#9402; Cell Signaling Technology;), IL-11 (\#sc-7924; Santa Cruz Biotechnology;), toll-like receptor 2 (TLR2; \#ab213676; Abcam;), B220 (\#550286; BD Biosciences, Franklin Lakes, NJ), CD3 (\#553058; BD Biosciences), CD45 (\#550539, BD Biosciences), and concentrationmatched rabbit-IgG control (\#I-1000; Vector Laboratories, Burlingame, CA). Following overnight $4^{\circ} \mathrm{C}$ incubations, sections were incubated at room temperature with biotinylated anti-rabbit IgG antibodies (Vector Laboratories; \#BA-1000), biotin-labeled with horseradish peroxidase (VECTASTAIN ABC HRP Kit; Vector Laboratories), and developed by using liquid diaminobenzidine chromogen substrate (Agilent Technologies, Santa Clara, CA). For PCNA, the Mouse on Mouse (M.O.M) detection kit (Vector Laboratories) was used. All sections were counterstained with hematoxylin, and images were acquired by using
cellSens Dimension software version 1.7.1 (Olympus, Tokyo, Japan).

Positive immunohistochemical staining intensity on human sections was determined by using the Aperio Positive Pixel Count Algorithm version 9.0 on whole slide scans (Aperio AT Turbo digital pathology scanner; Leica Biosystems, Wetzlar, Germany) of stained sections, and positivity was calculated as the total number of positive pixels per the total number of pixels (maximum score $=1$ ). To quantify positive immunohistochemical staining for B220, CD3, CD45, and PCNA on mouse sections, positive cells per $60 \times$ high-power field (HPF; $n=10$ ) were counted for a random WT broth (CD45 and PCNA) or WT Hf (B220 and CD3) sample, and arbitrarily assigned a value $=1$. Similarly, gastric (epithelial) glands positive for acidic mucins (according to Alcian blue/PAS [blue-purple] staining) were counted per $40 \times \operatorname{HPF}(n=10)$ containing equivalent numbers of glands for a random WT $H f$ sample; they were arbitrarily assigned a value $=1$. The number of positive cells (B220, CD3, CD45, and PCNA) or acidic mucin-containing glands for all other samples within each immunohistochemical staining group were then calculated relative to that sample. To quantify mucosal thickness, whole H\&E stained slides were scanned; mucosal thickness was then measured at 10 random points by using the linear measurement tool (Aperio ImageScope software version 12.4; Leica Biosystems), and the average measurement was used.

\section{Statistical Analysis}

All statistical analyses were performed by using GraphPad Prism software version 7.0 (GraphPad, San Diego, CA). Statistical significance $(P<0.05)$ between the means of two groups was determined by using $t$-tests or $U$-tests. Statistical significance between the means of multiple groups was determined by using ordinary one-way analysis of variance or Kruskal-Wallis tests. All data are expressed as the means \pm SEM.

\section{Results}

\section{STAT3 Serine Phosphorylation Is Constitutively Expressed in H. pylori-Associated Human Gastritis}

Because pY-STAT3 is up-regulated in $H$. pylori-positive $\left(\mathrm{Hp}^{+}\right)$gastritis patients, ${ }^{6}$ levels of immunohistochemical staining for pY-STAT3 and pS-STAT3 were initially compared in patient endoscopic gastric biopsy specimens. These specimens were stratified into gastritis $\left(\mathrm{Hp}^{-}\right.$and $\mathrm{Hp}^{+}$) or gastritis-free (normal) categories according to 
clinical pathology grading, the latter cohort being $\mathrm{Hp}^{-}$. In gastritis-free biopsy specimens, little to no pY-STAT3 staining was evident, whereas significantly increased staining (weak to moderate intensity) of cells positive for pS-STAT3 was observed in epithelial and stromal immune cell compartments (Figure 1). In $\mathrm{Hp}^{-}$and $\mathrm{Hp}^{+}$gastritis samples, pY-STAT3-positive staining was up-regulated fourfold and sixfold (albeit not significantly), respectively, compared with gastritis-free patient biopsy specimens (Figure 1B). In $\mathrm{Hp}^{-}$gastritis samples, pY-STAT3 staining of only weak intensity was primarily observed in immune cells, whereas weak to moderate stained pY-STAT3-positive cells were observed in both epithelial and immune cell compartments of $\mathrm{Hp}^{+}$gastritis samples (Figure 1A). Elevated pS-STAT3-positive staining of weak to moderate intensity was observed in both epithelial and stromal compartments of $\mathrm{Hp}^{-}$and $\mathrm{Hp}^{+}$ gastritis biopsy samples compared with pY-STAT3 staining in the corresponding biopsy samplesies (Figure 1). Furthermore, the level of pS-STAT3-positive cell staining in gastritis-free normal biopsy specimens was comparable to that of pY-STAT3-positive staining in both $\mathrm{Hp}^{-}$and $\mathrm{Hp}^{+}$gastritis biopsy specimens (Figure 1). Notably, in $\mathrm{Hp}^{+}$gastric cancer tumor biopsy specimens, pS-STAT3 levels were also comparable to gastritis-free and gastritis $\left(\mathrm{Hp}^{-}\right.$and $\left.\mathrm{Hp}^{+}\right)$biopsy specimens, whereas pY-STAT3 levels were highest versus gastritis-free and gastritis $\left(\mathrm{Hp}^{-}\right.$and $\left.\mathrm{Hp}^{+}\right)$biopsy specimens (Figure 1). These data therefore suggest that pS-STAT3 is constitutively expressed in the human gastric compartment irrespective of $H$. pylori status or the presence of gastritis.

\section{Constitutive STAT3 Serine Phosphorylation Promotes H. felis-Mediated Gastric Pathology in Mice}

To further assess the role of pS-STAT3 in Helicobacterassociated gastric disease, a 4-month $H$. felis infection model that reproducibly mimics chronic active gastritis and gastric epithelial hyperplasia (the latter evidenced by a marked increase in mucosal thickness) of human gastric pathology after $H$. pylori infection (Figure 2A) was used. ${ }^{2,30-33}$ Consistent with previous Helicobacter infection models, ${ }^{4,6}$ immunohistochemistry revealed increased $\mathrm{pY}$ STAT3-positive staining of moderate to strong intensity in the epithelium and immune/inflammatory infiltrates in the gastric corpus of $\mathrm{H}$. felis-infected WT mice versus brothgavaged WT mice (Figure 2B). By contrast, immunohistochemistry indicated that gastric pS-STAT3 staining of weak to moderate intensity was comparable between the $H$. felis-infected WT mice and their broth control counterparts (Figure 2C). Collectively, these observations suggest that in contrast to pY-STAT3, which is up-regulated in Helicobacter-infected tissue, pS-STAT3 is constitutively expressed in the gastric mucosa (mouse and human) irrespective of Helicobacter status.
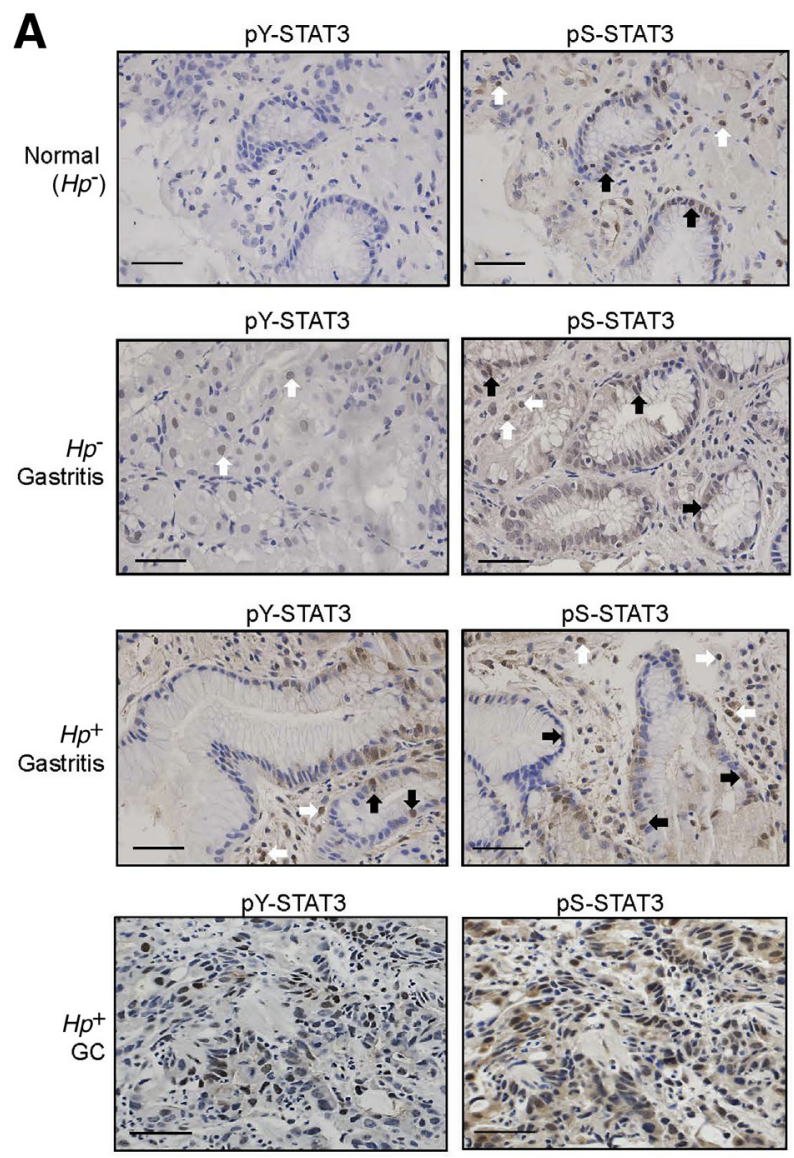

pS-STAT3
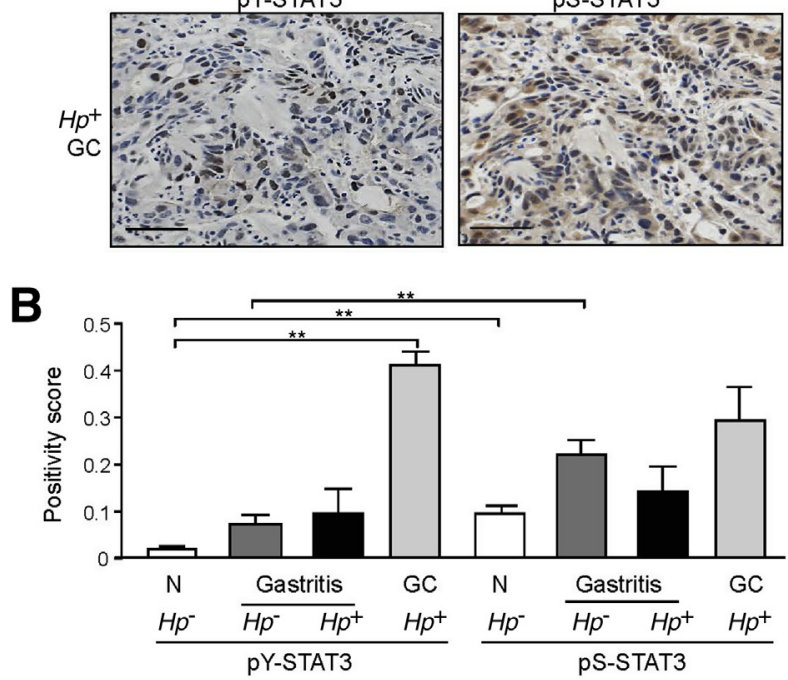

Figure 1 STAT3 serine 727 phosphorylation is constitutively expressed in human gastric corpus biopsy samples. A: Representative photomicrographs of cross-sections from gastric corpus biopsy specimens from either Helicobacter pylori-negative $\left(\mathrm{Hp}^{-}\right)$gastritis-free normal individuals, $\mathrm{Hp}^{-}$and $\mathrm{Hp}$-positive $\left(\mathrm{Hp}^{+}\right)$gastritis patients, or $\mathrm{Hp}^{+}$gastric cancer (GC) patients, stained for pTyr705-STAT3 [tyrosine-phosphorylated (pY)-STAT3] or pSer727-STAT3 [serine-phosphorylated (pS)-STAT3]. White and black arrows point to positivity for the indicated antibody staining in immune and epithelial cells, respectively. B: Staining positivity for pY-STAT3 and pS-STAT3 was quantitatively determined by using Aperio ImageScope analysis software version 12.4. Data are expressed as means \pm SEM. $n=15$ $\mathrm{Hp}^{-}$gastritis-free normal individuals (A); $n=23 \mathrm{Hp}^{-}$and $\mathrm{Hp}^{+}$gastritis patients (A); $n=20 \mathrm{Hp}^{+} \mathrm{GC}$ patients (A); $n=5$ per patient group (B). ${ }^{* *} P<0.01$ (Kruskal-Wallis test). Scale bars $=50 \mu \mathrm{m}$.

To define whether constitutive pS-STAT3 is required for Helicobacter-induced gastric pathology, WT and pS-STAT3-deficient Stat ${ }^{\mathrm{SA} / \mathrm{SA}}$ mice were subjected to the 4-month $H$. felis infection model. Immunoblotting of gastric 

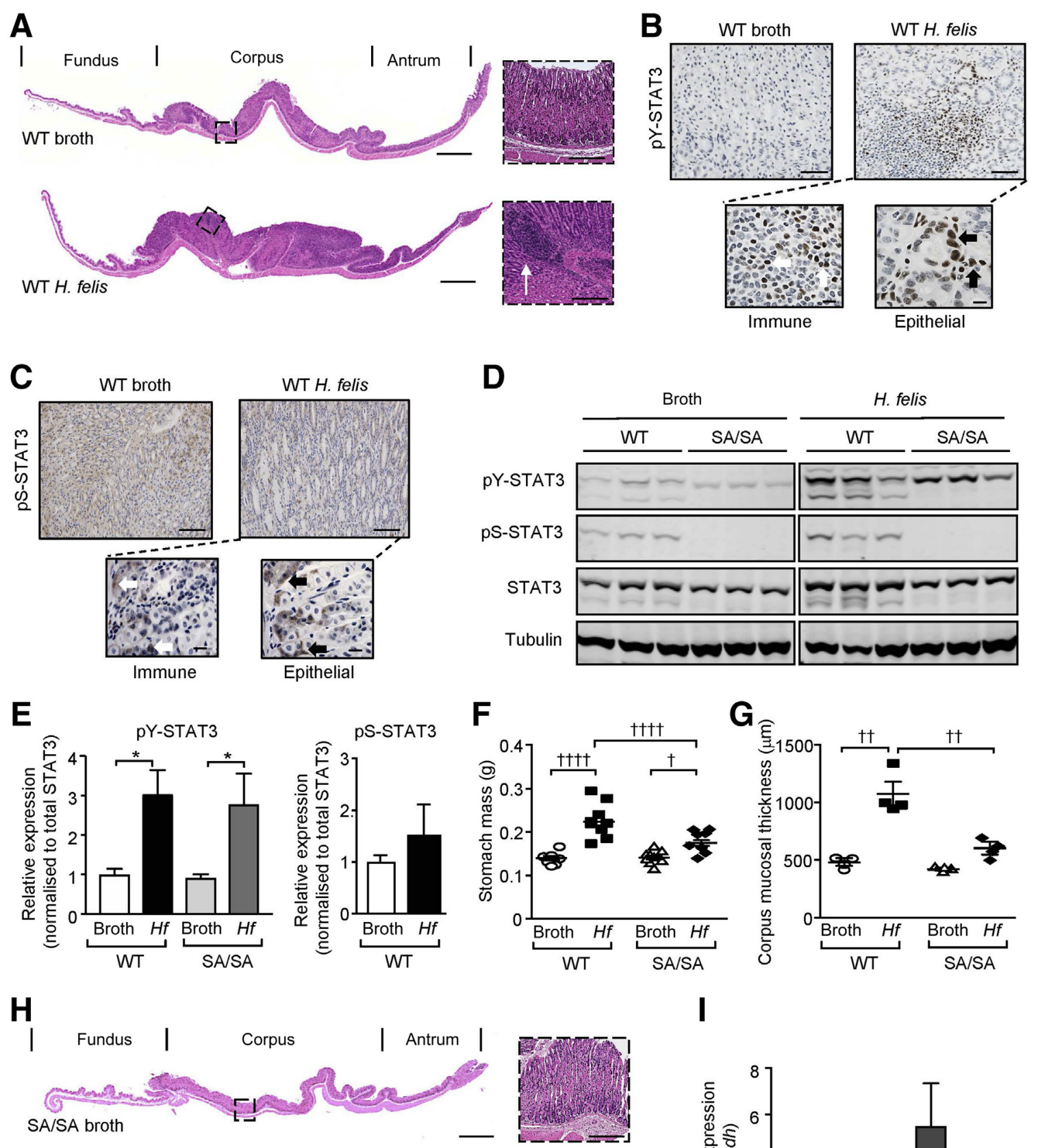

I
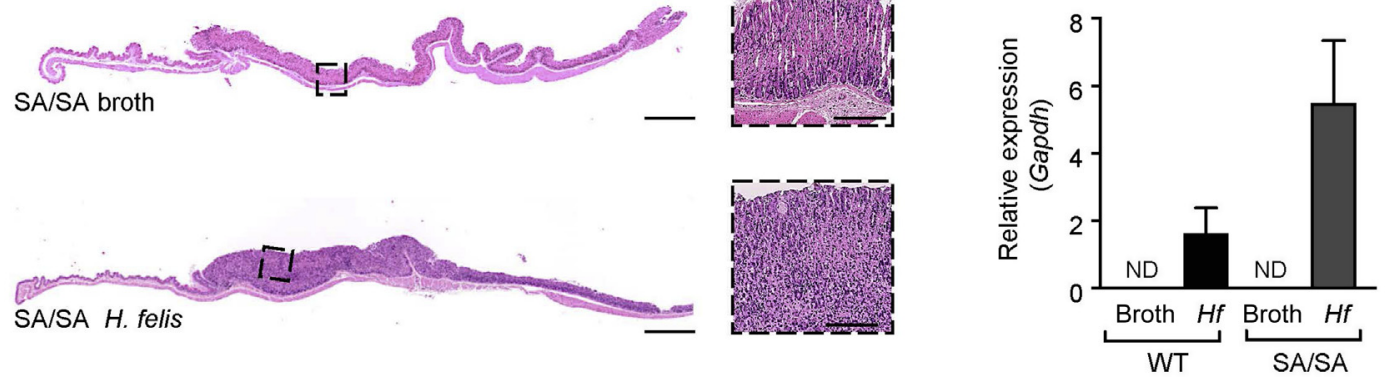

Figure 2 STAT3 serine 727 phosphorylation promotes Helicobacter felis-mediated gastric pathology in mice. A: Low-power images of hematoxylin and eosin-stained whole stomach longitudinal cross-sections with corresponding magnification (dashed boxes are enlarged to the right) of the corpus mucosa from the indicated groups. Arrow indicates an inflammatory aggregate. B and C: Representative low-power images (top rows) of gastric corpus cross-sections from broth or $H$. felis-gavaged wild-type (WT) mice (four mice per group) stained with antibodies against tyrosine-phosphorylated (pY)-STAT3 (B) or serine-phosphorylated (pS)-STAT3 (C). Magnified images (bottom rows) show pY-STAT3 (B) or pS-STAT3 (C) positivity in epithelial (black arrows) and immune (white arrows) cell compartments. D: Immunoblots of lysates from gastric corpus tissues of WT and Stat $3^{\mathrm{SA} / \mathrm{SA}}(\mathrm{SA} / \mathrm{SA})$ mice, 4 months after receiving either broth or $\mathrm{H}$. felis $(\mathrm{Hf})$, with the indicated antibodies. Each lane represents an individual mouse. E: Densitometry quantification of pY-STAT3 and pS-STAT3 levels from the immunoblot in D. F and G: Scatter plots depicting total mass (grams) of stomachs (F) and corpus mucosal thickness (G) from the indicated groups of WT and SA/SA mice. H: Low-power images of hematoxylin and eosin-stained whole stomach longitudinal cross-sections with corresponding magnification (dashed inset) of the corpus mucosa from the indicated groups. I: $H$. felis colonization of corpus tissue determined by using quantitative real-time PCR from genomic DNA of stomachs from the indicated WT and SA/SA groups. Expression data of $H$. felis - specific flaB relative to murine-specific Gapdh are presented from technical triplicates. Data are expressed as means $\pm \mathrm{SEM}(\mathbf{E}, \mathbf{F}, \mathbf{G}$, and $\mathbf{I})$. $n=3$ per group $(\mathbf{D}) ; n=8$ mice per group (F); $n=4$ mice per group (G); $n=5$ per group (I). ${ }^{*} P<0.05$ ( $t$-test); ${ }^{\dagger} P<0.05,{ }^{\dagger \dagger} P<0.01$, and ${ }^{\dagger \dagger \dagger^{\dagger} P}<0.0001$ (one-way analysis of variance). Scale bars $=1 \mathrm{~mm}$ (A and $\mathbf{H}$, main images); $200 \mu \mathrm{m}$ (A and $\mathbf{H}$, magnifications); $100 \mu \mathrm{m}$ (B and $\mathbf{C}$, top row); $10 \mu \mathrm{m}$ (B and $\mathbf{C}$, bottom row). ND, threshold cycle values not determined. 
lysates revealed a significant and equivalent up-regulation of pY-STAT3 in infected WT and Stat $3^{\mathrm{SA} / \mathrm{SA}}$ mice, whereas basal constitutive pS-STAT3 levels were not significantly altered in infected WT mice (Figure 2, D and E). In WT and Stat $3^{\mathrm{SA} / \mathrm{SA}}$ mice inoculated with broth only, stomach mass and gastric corpus mucosal thickness were phenotypically indistinguishable (Figure 2, A and $\mathrm{F}-\mathrm{H}$ ). However, $H$. felis-infected WT mice exhibited significant increases in stomach mass (70\%) and corpus mucosal thickness (140\%) compared with broth control mice (Figure 2, F and G). By contrast, although $H$. felis infection of Stat $3^{\mathrm{SA} / \mathrm{SA}}$ mice increased stomach mass $(20 \%)$ and corpus mucosal thickness $(40 \%)$ compared with Stat $3^{\mathrm{SA} / \mathrm{SA}}$ broth control mice, these gastric parameters in $H$. felis-infected Stat $3^{\mathrm{SA} / \mathrm{SA}}$ mice were significantly reduced compared with infected WT mice (Figure 2, F and G). The suppressed H. felis-driven gastric pathology in Stat $^{\mathrm{SA} / \mathrm{SA}}$ mice was not due to the inability of $H$. felis to colonize Stat $3^{\mathrm{SA} / \mathrm{SA}}$ mouse stomachs, as qPCR expression analysis of the H. felis-specific $\mathrm{flaB}$ gene showed that the gastric corpus bacterial loads of $H$. felis were increased (albeit not significantly) in infected Stat $3^{\mathrm{SA} / \mathrm{SA}}$ mice compared with WT counterparts (Figure 2I). Taken together, these data show an essential requirement of pS-STAT3 by $\mathrm{H}$. felis to promote host gastric pathologic changes.

\section{STAT3 Serine Phosphorylation Promotes}

\section{H. felis-Mediated Inflammation, Proliferation, and IM} in the Gastric Mucosal Epithelium

The reduced stomach mass and mucosal thickness of H. felis-infected Stat $3^{\mathrm{SA} / \mathrm{SA}}$ mice suggest that the absence of pS-STAT3 suppressed the inflamed gastric hyperproliferative phenotype that is associated with chronic Helicobacter infection. ${ }^{2,30-33}$ We therefore assessed the magnitude of inflammation in gastric sections from infected WT and Stat $3^{\mathrm{SA} / \mathrm{SA}}$ mice by immunostaining for $\mathrm{CD} 45$, a panleukocyte (ie, inflammatory cell) marker. As shown in Figure 3A, CD45-positive inflammatory/immune cell infiltrates and aggregates were observed throughout the gastric mucosal, submucosal, and muscularis compartments of infected WT mice compared with broth control mice. Additional immunohistochemistry performed on serial gastric sections confirmed that these CD45-positive inflammatory infiltrates were predominantly B220-positive B cells and, to a lesser extent, CD3-positive T cells (Figure 3B). By contrast, the extent of positive staining for CD45, B220, and CD3 was markedly diminished in the gastric corpus of $H$. felis-infected Stat $^{\mathrm{SA} / \mathrm{SA}}$ mice (Figure 3, A-C). In further support of an ameliorated gastric inflammatory phenotype of infected Stat $3^{\mathrm{SA} / \mathrm{SA}}$ mice, the gastric expression profile of numerous proinflammatory genes up-regulated in response to Helicobacter infection was significantly reduced in infected Stat $3^{\mathrm{SA} / \mathrm{SA}}$ mice versus WT mice (Figure 3D).

Next, it was assessed whether the suppressed gastric pathology in $H$. felis-infected Stat $3^{\mathrm{SA} / \mathrm{SA}}$ mice was the consequence of a reduced proliferative potential of the gastric epithelium. In $H$. felis-infected WT mice, immunostaining for PCNA, a marker of actively dividing cells, revealed that PCNA-positive staining intensity in the corpus mucosa was markedly elevated compared with that in broth WT control mice; it was also characterized by an expanded proliferative zone, concomitant with noticeable increases in gland length and overall mucosal thickness (Figures $2 \mathrm{G}$ and 4A). By contrast, in infected Stat $3^{\mathrm{SA} / \mathrm{SA}}$ mice, the proliferative zone was narrowly confined to the isthmus of the corpus mucosa, and along with substantially reduced levels of PCNA staining, was comparable to broth control WT and Stat ${ }^{\mathrm{SA} / \mathrm{SA}}$ mice (Figure 4, A and B). The reduced proliferative potential of the corpus epithelium of infected Stat $3^{\mathrm{SA} / \mathrm{SA}}$ mice was verified at the molecular level, whereby mRNA levels for numerous cell cycle progression genes implicated in gastric carcinogenesis, namely $c-M y c, C d 44$, and $C c n d 2,{ }^{34-36}$ were significantly reduced in the corpus of $\mathrm{H}$. felis-infected Stat $3^{\mathrm{SA} / \mathrm{SA}}$ mice versus WT mice (Figure $4 \mathrm{C}$ ). Among these cell proliferation markers, representative immunohistochemical staining for c-Myc verified the strong protein expression predominantly in the gastric glandular epithelium of infected WT mice compared with Stat $^{\mathrm{SA} / \mathrm{SA}}$ mice (Supplemental Figure S1A).

Because Helicobacter-induced gastric pathology is also associated with IM, it was assessed whether the absence of pS-STAT3 would also suppress the onset of IM. Indeed, Alcian blue/PAS staining of gastric tissue sections to detect acidic mucins that are characteristic of IM indicated the pronounced absence of acid mucin-producing goblet cells [blue-purple staining, caused by a combination of intestinal acid (blue staining) and gastric neutral (magenta staining) mucins] in $H$. felis-infected Stat $3^{\mathrm{SA} / \mathrm{SA}}$ mice compared with WT mice (Figure 4, D and E). In addition, the expression of the intestinal mucin-encoding genes $\mathrm{Mucl}$ and $\mathrm{Muc2}$ was significantly lower in the stomachs of $H$. felis-infected Stat $3^{\mathrm{SA} / \mathrm{SA}}$ mice versus WT mice (Figure 4F). Taken together, these data indicate that pS-STAT3 is required for pre-neoplastic Helicobacter-induced gastritis, hyperplasia, and IM lesions within the gastric compartment.

\section{Serine 727 Phosphorylation Is Required for Maximal STAT3 Transcriptional Activity to Support H. felis-Mediated Gastric Disease}

The pro-oncogenic potential of pS-STAT3 has been attributed to numerous cellular processes, ranging from a canonical nuclear role in mediating maximal STAT3 transcriptional activity, to a mitochondrial role in which pSSTAT3 supports mitochondrial function and regulates cellular metabolism. ${ }^{10-12,15,16,18}$ We therefore assessed whether pS-STAT3 contributed to the transcriptional activity of numerous bona fide STAT3 target genes implicated in gastric tumorigenesis. ${ }^{21,37}$ As shown in Figure 5A, gastric gene expression levels of Socs3, Stat3 (a target of itself), Ill1, and Tlr2 were significantly up-regulated in response to 
A

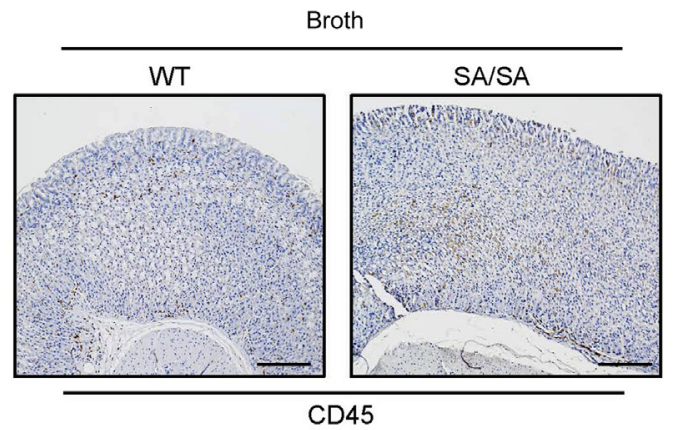

B

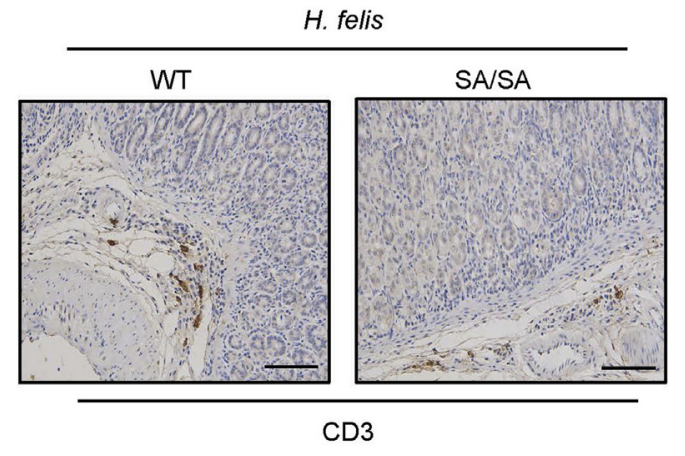

H. felis

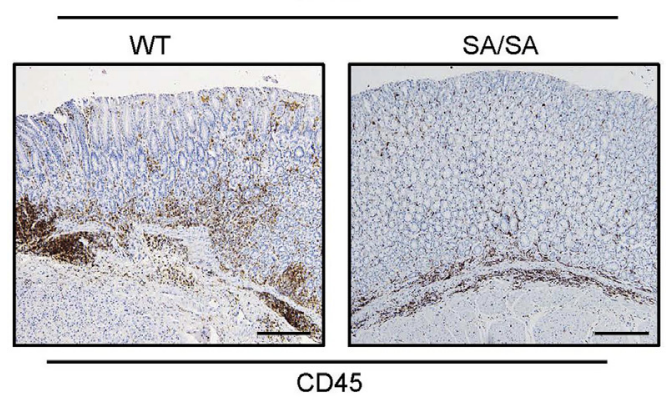

H. felis

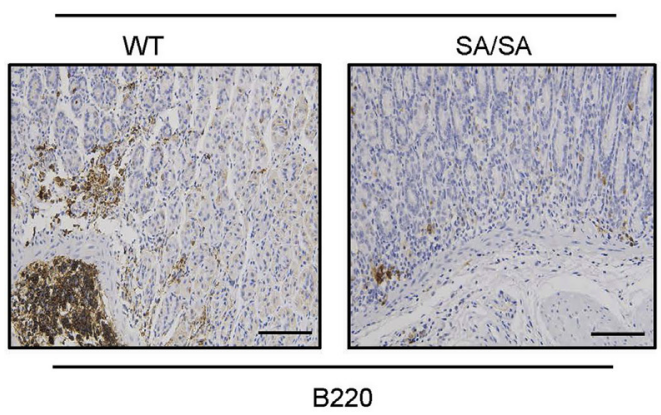

CD3

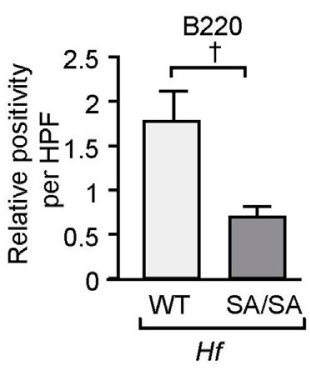

D
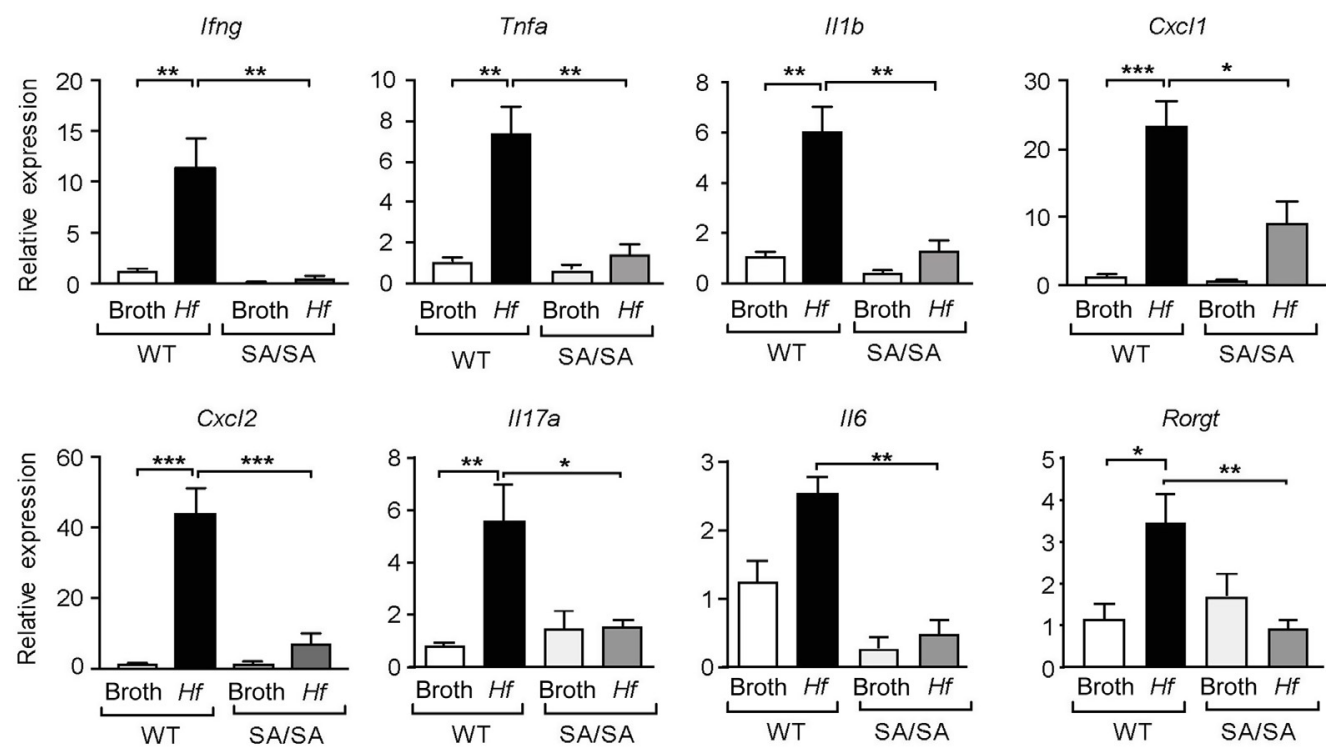

Figure 3 STAT3 serine 727 phosphorylation drives mucosal inflammation in response to Helicobacter felis infection. A and B: Representative images (from four mice per group) CD45-stained (A) and CD3- and B220-stained (B) gastric corpus cross-sections from wild-type (WT) and Stat3 $3^{\text {SA/SA }}$ (SA/SA) mice after 4 months of receiving either broth or $\mathrm{H}$. felis $(\mathrm{Hf})$. C: Graphs representing quantification of relative immunohistochemical staining positivity, presented per highpower field (HPF), with the indicated antibodies. D: Quantitative real-time PCR analyses of the indicated genes, relative to the 18s rRNA housekeeping gene, in corpus gastric tissue from the indicated mouse groups. Analyzed genes are: Lfng, Inf (alias Infa), Il1b, Cxcl1, Cxcl2, Il17a, Il6. Data are from technical

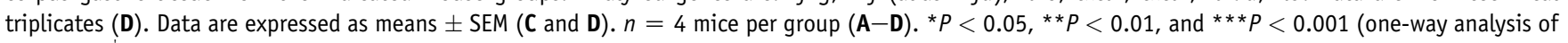
variance); ${ }^{\dagger} P<0.05$ (t-test). Scale bars $=100 \mu \mathrm{m}$ (A and $\left.\mathbf{B}\right)$. 
A

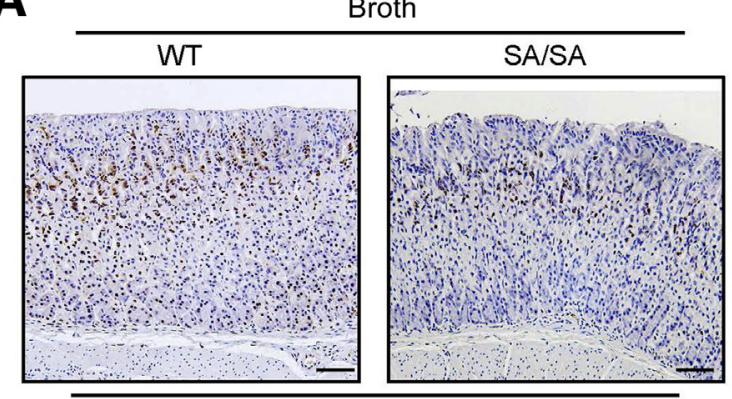

PCNA

B

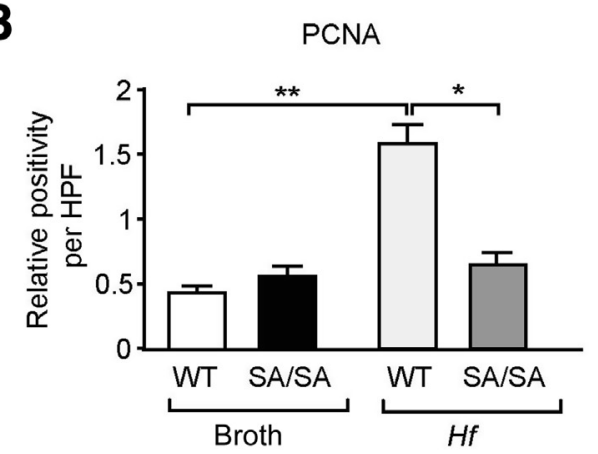

D

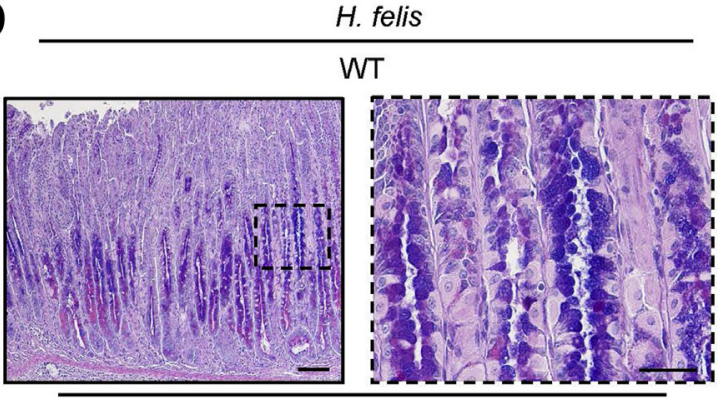

Alcian blue/PAS

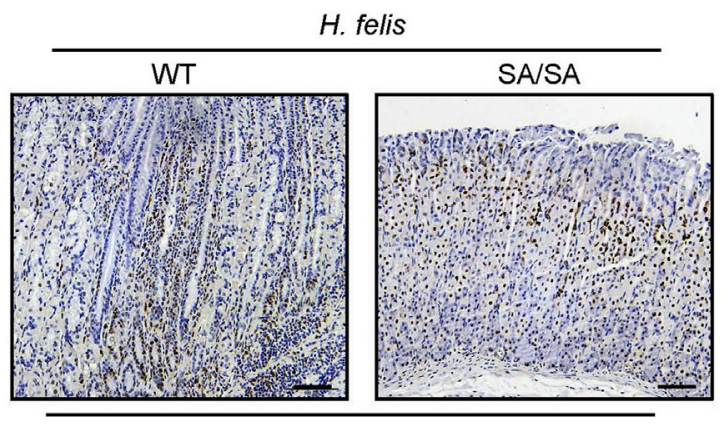

PCNA
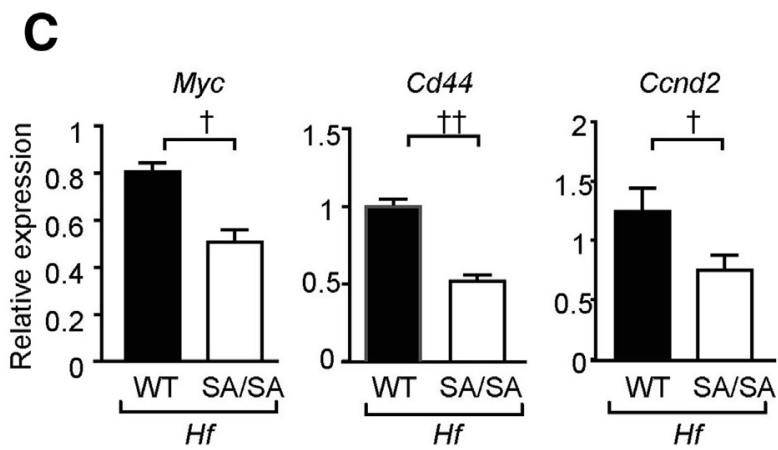

H. felis

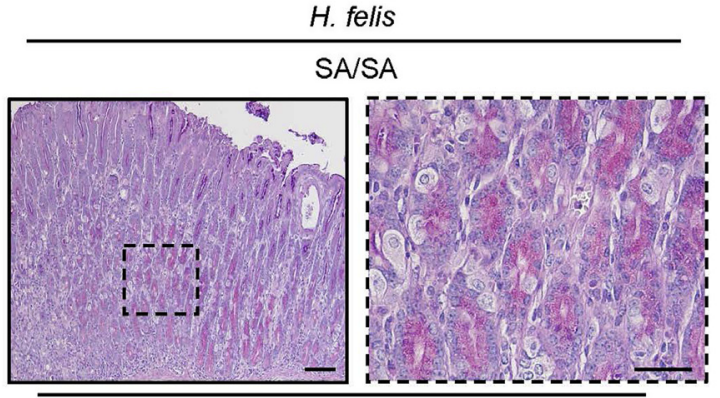

Alcian blue/PAS
E

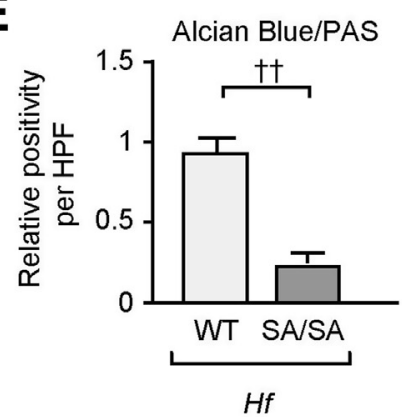

F

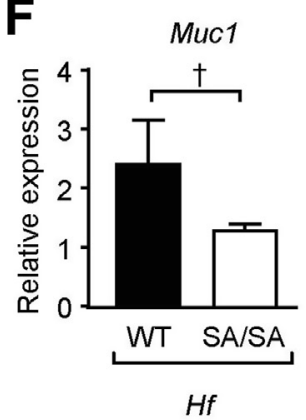

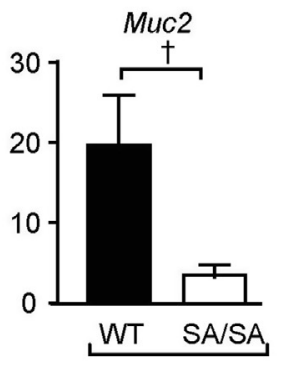

Hf

Figure 4 Signal transducer and activator of transcription 3 (STAT3) serine 727 phosphorylation drives mucosal cellular proliferation and intestinal metaplasia in response to Helicobacter felis infection. A: Representative images of proliferating cell nuclear antigen (PCNA)-stained gastric corpus crosssections from wild-type (WT) and Stat $3^{\mathrm{SA} / \mathrm{SA}}$ (SA/SA) mice after 4 months of receiving either broth or $\mathrm{H}$. felis ( $H$ f). B: Graph representing quantification of relative PCNA immunohistochemical staining positivity, presented per high-power field (HPF). C: Quantitative real-time PCR expression analyses of cell proliferation genes (normalized against 18s rRNA) in gastric tissues from the indicated mouse groups. Analyzed genes include Myc, CD44, and CCnd2. D: Representative low-power (left) and high-power (right) photomicrographs showing Alcian blue/periodic acid-Schiff (PAS)-stained cross-sections through the gastric corpus region of the indicated mouse groups. Dashed boxes are shown at higher magnification on the right. Neutral mucins stain magenta, and acid mucins stain dark blue/purple. E: Graph representing quantification of acid mucin-containing gastric glands (dark blue/purple Alcian blue/PAS staining) presented per HPF. F: Quantitative real-time PCR expression analyses of Muc1 and Muc2 (normalized against 18s rRNA) in gastric tissues from the indicated mouse groups. Data are expressed as means \pm SEM $(\mathbf{B}, \mathbf{C}$, and $\mathbf{D}-\mathbf{F})$. Data are presented from technical triplicates $(\mathbf{C}$ and $\mathbf{F})$. $n=4$ mice per group $(\mathbf{A}, \mathbf{D}$, and $\mathbf{E}) ; n=5$ mice per group (C and $\mathbf{F}) .{ }^{*} P<0.05,{ }^{*} P<0.01$ (one-way analysis of variance); ${ }^{\dagger} P<0.05,{ }^{\dagger} P<0.01$ ( $t$-test). Scale bars $=100 \mu \mathrm{m}(\mathbf{A}$, and $\mathbf{D}$, main images); $50 \mu \mathrm{m}$ (D, magnifications). 

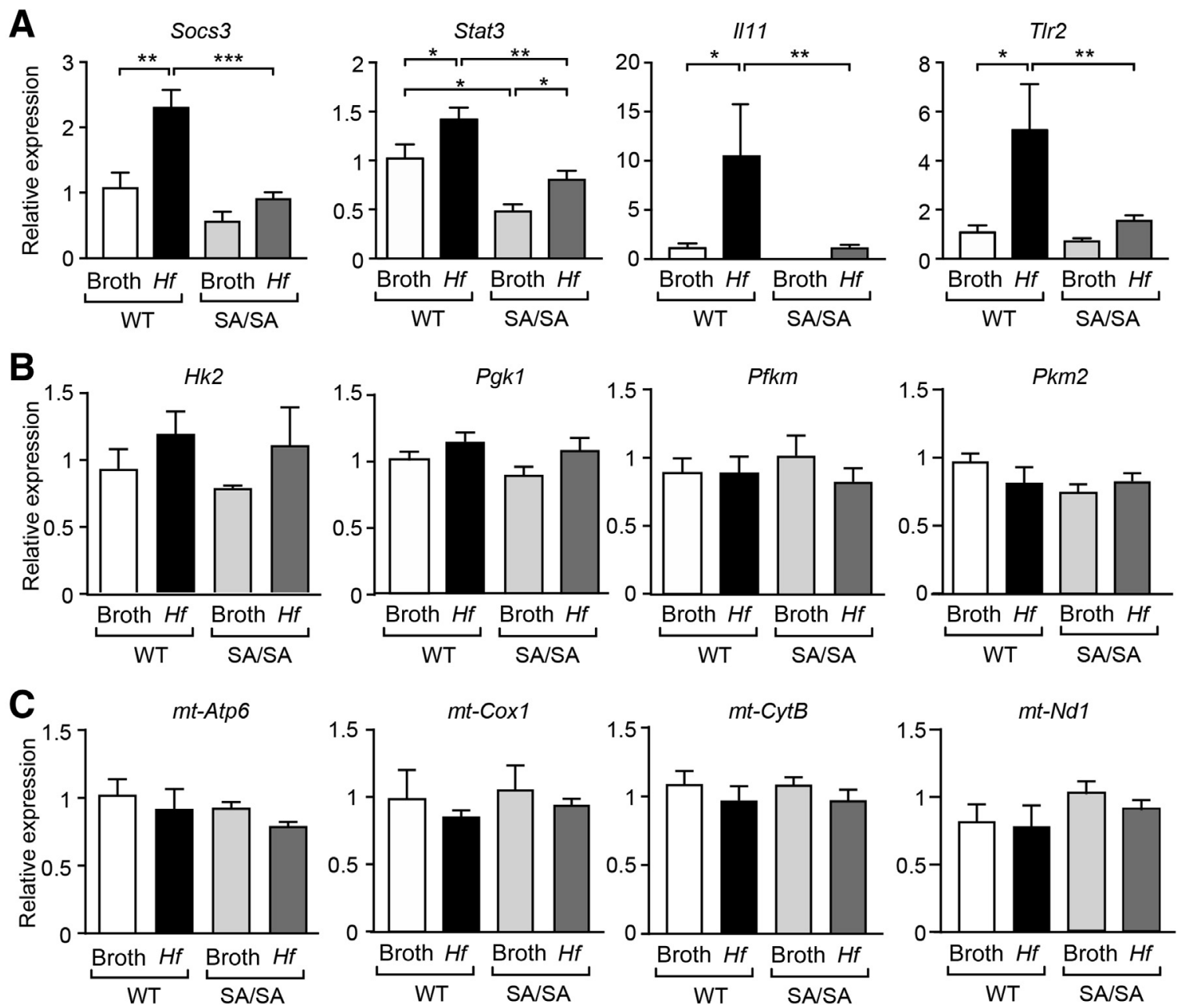

Figure 5 Serine phosphorylation of STAT3 is required for maximal expression of STAT3 target genes, but not metabolic or mitochondrial function gene networks, during Helicobacter felis infection. Quantitative real-time PCR expression analyses of the indicated genes (normalized against $18 s$ rRNA) in gastric tissues from wild-type (WT) and Stat3 ${ }^{\mathrm{SA} / \mathrm{SA}}$ (SA/SA) mice after 4 months of receiving either broth or $\mathrm{H}$. felis (Hf). Analyzed genes include Socs3, Il11, Tlr2, Hk2, $P g k 1, P f k m, P k m$ (alias $P k m 2), m t-A t p 6, m t-C y t B$. Data are presented from technical triplicates. Data are expressed as means \pm SEM. $n=5$ per group (A-C). ${ }^{*} P<0.05,{ }^{* *} P<0.01$, and ${ }^{* * *} P<0.001$ (t-test).

chronic $H$. felis infection in WT mice. However, in $H$. felis-infected Stat $^{\mathrm{SA} / \mathrm{SA}}$ mice, despite increased $\mathrm{pY}$ STAT3 levels similar to those in infected WT mice (Figure 2D), the expression of this STAT3-regulated gene signature was significantly reduced compared with that in infected WT mice (Figure 5A). Consistent with these findings, immunohistochemical staining showed strong protein expression of IL-11 and TLR2 in both immune (lamina propria and submucosal regions) and glandular epithelial cells within the $H$. felis-infected gastric compartment of WT mice, which was markedly lower in the infected Stat $3^{\mathrm{SA} / \mathrm{SA}}$ mice (Supplemental Figure S1, B and C). These data suggest that serine, rather than tyrosine, phosphorylation plays a significant role in modulating the transcriptional activity of STAT3 during $H$. felis-mediated gastric pathology.

It was assessed whether the absence of pS-STAT3 affected metabolic events at the molecular level by profiling the expression of representative genes encoding key components of glycolysis ( $H k 2, P f k m, P g k l$, and $P k m 2)$. However, gastric mRNA levels of these genes were unchanged in WT and Stat $3^{\mathrm{SA} / \mathrm{SA}}$ mice inoculated with broth or $\mathrm{H}$. felis (Figure 5B). Similarly, the expression profiles of a series of mitochondrial-encoded genes, used as a molecular readout for mitochondrial function, were comparable in WT and Stat $3^{\mathrm{SA} / \mathrm{SA}}$ mice irrespective of $\mathrm{H}$. felis infection (Figure 5C). These data therefore suggest that pS727 is required for maximal transcriptional output of STAT3-regulated genes during chronic Helicobacter infection.

\section{IL-11 Signaling Promotes H. felis-Mediated Gastric Pathology}

IL-11 expression levels are elevated in patients with gastric cancer and correlate with disease severity. ${ }^{19,22,37}$ In addition, 

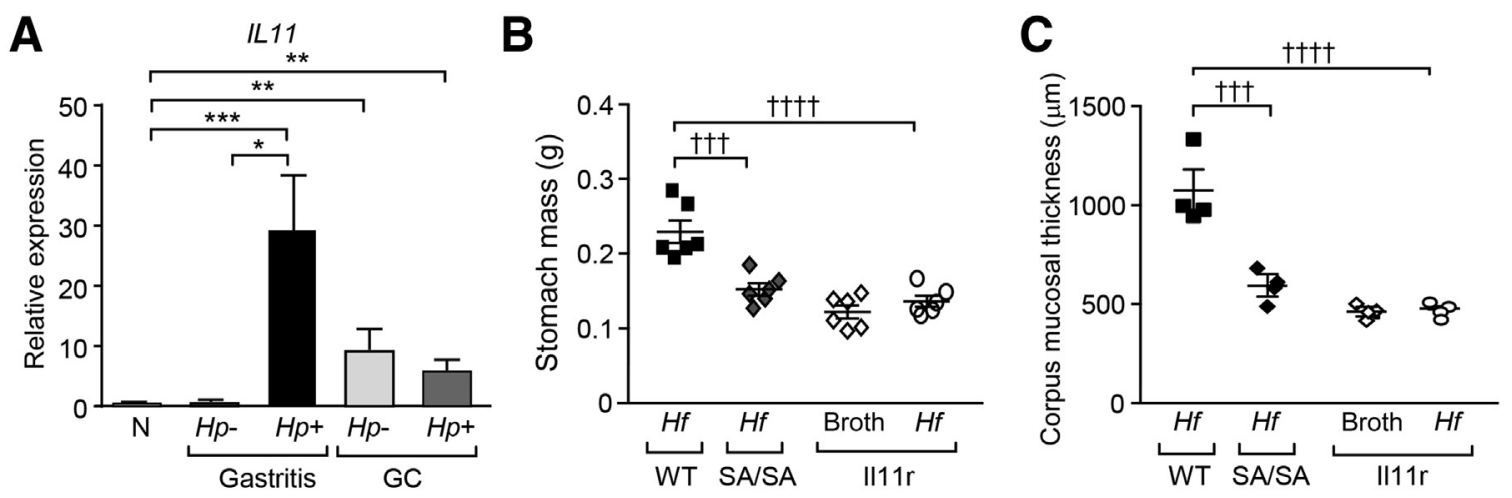

D
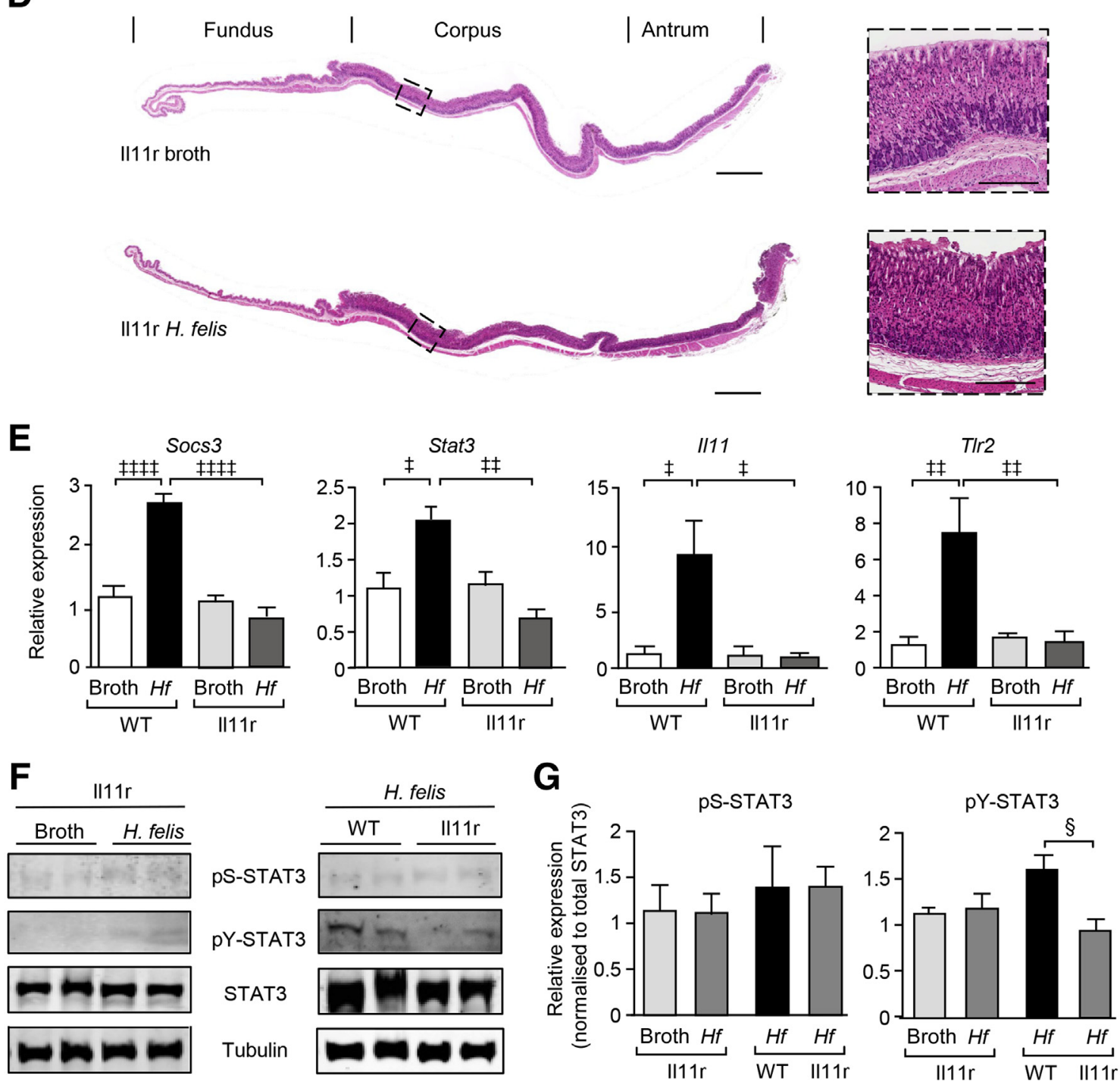

Figure 6 IL-11 signaling promotes Helicobacter felis-mediated gastric inflammation. A: Quantitative real-time PCR gene expression analysis of IL11 (normalized against $18 \mathrm{~S} r R N A)$ in gastric biopsy samples from either normal Helicobacter pylori-negative individuals $(\mathrm{N}), \mathrm{H}$. pylori-negative $\left(\mathrm{Hp}^{-}\right)$or $\mathrm{H}$. pylori-positive $\left(\mathrm{Hp}^{+}\right)$patients with gastritis, or from tumors of patients with gastric cancer $(\mathrm{GC})$ who are $\mathrm{Hp}^{-}$or $\mathrm{Hp}^{+}$. B and C: Scatter plots depicting the total mass (grams) of stomachs (B) and corpus

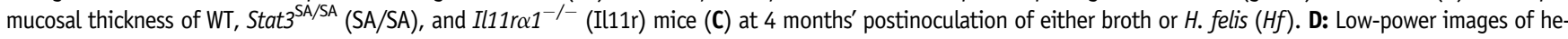
matoxylin and eosin-stained whole stomach longitudinal cross-sections with corresponding magnification (dashed boxes enlarged to the right) of the corpus mucosa from the indicated groups. E: Quantitative real-time PCR expression analyses of STAT3-target genes (normalized against 18s rRNA) in gastric tissues from the indicated mouse groups. Analyzed genes include Socs3, Stat3, Il11, and Tlr2. F: Immunoblots of lysates from gastric corpus tissues of the indicated mice with the specified antibodies. Each lane represents an individual mouse. G: Densitometry quantification of serine phosphorylated (pS)-STAT3 and tyrosine phosphorylated (pY)-STAT3 expression levels relative to total STAT3. Data are expressed as means \pm SEM $(\mathbf{A}-\mathbf{C}, \mathbf{E}$, and $\mathbf{G})$. Data are presented from technical triplicates $(\mathbf{A}$ and $\mathbf{E}) . n=10 \mathrm{~N}$ and $H p^{+}(\mathbf{A}) ; n=6 H p^{-}(\mathbf{A}) ; n=7$ patients with $\mathrm{GC}$ who are $\mathrm{Hp}^{-}(\mathbf{A}) ; n=13$ patients with $\mathrm{GC}$ who are or $\mathrm{Hp}^{+}(\mathbf{A}) ; n=6$ mice per group $(\mathbf{B}) ; n=4$ mice per group $(\mathbf{C}) ; n=5$ per group $(\mathbf{E}) ; n=2$ representative immunoblots comprising 6 samples per group $(\mathbf{G}) .{ }^{*} P<0.05,{ }^{* *} P<0.01$, and ${ }^{* * * P} P 0.001$ (Kruskal-Wallis test); ${ }^{\dagger \dagger \dagger} P<0.001,{ }^{\dagger \dagger \dagger} P<0.0001$ (one-way analysis of variance); ${ }^{\ddagger} P<0.05,{ }^{\ddagger \ddagger} P<0.01$, and ${ }^{\ddagger \ddagger \ddagger \ddagger} P<0.0001$ ( $t$-test); ${ }^{\S} P<0.05$ (one-way analysis of variance). Scale bars: 1 mm (D, main images); $200 \mu \mathrm{m}$ (D, magnifications). 
elevated STAT3-dependent expression of the IL-11 cytokine is essential for gastric inflammation-associated tumorigenesis in a spontaneous, genetically modified mouse model for intestinal-type gastric adenocarcinoma. ${ }^{21}$ Because $I l l 1$ was significantly up-regulated in gastric tissues of $\mathrm{H}$. felis-infected mice in a pS-STAT3-dependent manner (Figure 5A), the expression of ILII in human gastric biopsy samples from patients with gastritis and gastritis-free individuals stratified according to $H$. pylori status was assessed next (Supplemental Table S1). qPCR revealed that gastric $I L 11$ mRNA levels are also significantly elevated in $\mathrm{Hp}^{+}$gastritis samples compared with biopsy samples from $\mathrm{Hp}^{-}$gastritis and gastritis-free individuals (Figure 6A). Consistent with previous findings, compared with normal gastric biopsy samples, IL11 gene expression was also significantly increased in tumors of patients with gastric cancer, albeit irrespective of their H. pylori infection status (Figure 6A). ${ }^{37}$

Considering that the transcriptional induction of $\mathrm{Ill1}$ during $H$. felis infection is dependent on upstream STAT3 serine phosphorylation in a disease-associated manner (Figure 5A), it was reasoned that the genetic ablation of IL11 signaling would phenocopy the suppressed development of gastric disease observed in Stat $3^{\mathrm{SA} / \mathrm{SA}}$ mice in response to chronic $H$. felis infection. Indeed, upon exposure of IL-11 receptor (IL-11R)-deficient mice $\left(\right.$ Ill1 $\mathrm{ral}^{-/-}$) to $\mathrm{H}$. felis infection for 4 months, no differences in either stomach mass or corpus mucosal thickness were observed compared with their broth-treated counterparts (Figure 6, B-D). Furthermore, stomach mass and mucosal thickness of $H$.

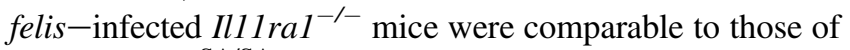
infected Stat $^{\mathrm{SA} / \mathrm{SA}}$ mice but significantly reduced compared with those of infected WT animals (Figure 6, B-D). The response of Ill1 ral ${ }^{-/-}$mice to Helicobacter infection was also comparable to that of Stat $3^{\mathrm{SA} / \mathrm{SA}}$ mice at the molecular level, as evidenced by the absence of any significant upregulation of STAT3 target genes (eg, Ill1) in the gastric compartment of infected $1111 \mathrm{ral}^{-/-}$mice (Figure 6E).

We had predicted that in $1111 \mathrm{ral}^{-1-}$ mice during Helicobacter infection, the absence of IL-11R (which upon IL11 binding, engages JAK-bound gp130 receptor complexes to induce pY-STAT3, independently of pS-STAT3) would lower pY-STAT3 levels. Consistent with this prediction, pY-STAT3 was only modestly up-regulated in infected Ill1 $\mathrm{ral}^{-1-}$ mouse stomachs compared with the strong upregulation of pY-STAT3 levels in infected WT mice (Figures 2D and 6, F and G). As expected, gastric pS-STAT3 levels remained unaltered in $H$. felis-infected Ill1 $\mathrm{ra}^{-1-}$ mice compared with the broth control mice, similar to our findings in infected WT mice (Figures 2D and $6, F$ and $\mathrm{G})$. This scenario thus supports the notion that IL$11 \mathrm{R}$ signaling is downstream of, and does not influence, constitutive pS-STAT3 levels during Helicobacter infection. Collectively, these data suggest that constitutive pSSTAT3 is required by IL-11 to promote gastric disease in response to chronic $H$. felis infection.

\section{Discussion}

The current study shows that STAT3 serine phosphorylation is a prerequisite for $\mathrm{H}$. felis-mediated gastritis, mucosal hyperplasia, and IM, which are key stages in the $\mathrm{H}$. pylo$r i$-driven human gastric carcinogenesis cascade. A key finding of our work was that pS-STAT3 levels are constitutive and remain largely unchanged in the context of $\mathrm{Hel}$ icobacter infection. This finding contrasts with that of $\mathrm{pY}$ STAT3, which is largely undetectable in the steady state yet dramatically increases in levels in response to infection, showing that Helicobacter predominantly triggers transduction pathways that tyrosine phosphorylate STAT3. Indeed, our observation in $\mathrm{H}$. felis-infected Stat $3^{\mathrm{SA} / \mathrm{SA}}$ mice that disease pathogenesis was suppressed despite pYSTAT3 being up-regulated, dissociates pY-STAT3 from Helicobacter-induced gastric pathology. A likely explanation for the differential regulation of serine and tyrosine phosphorylation of STAT3 is that pY-STAT3 is largely a consequence of a restricted number of kinases (ie, JAK, Src) whose activation is tightly regulated, for instance by IL11. 3,10,21 By contrast, STAT3 can be phosphorylated at S727 by a multitude of kinases, including extracellularregulated kinase, p38 and c-Jun $\mathrm{N}$-terminal kinase mitogen-activated protein kinases, protein kinase $\mathrm{C}$ delta, glycogen synthase kinase $3 \alpha / \beta$, and cyclin-dependent kinase-1; these kinases in turn are activated by a multitude of homeostatic stimuli that are present in most tissues. ${ }^{38-43}$ Therefore, constitutive pS-STAT3 is likely due to at least one upstream kinase being engaged at all times in tissues.

It was also observed that Stat $^{\mathrm{SA} / \mathrm{SA}}$ mice display levels of pY-STAT3 equivalent to those of WT mice during both steady state and chronic $H$. felis infection. This finding suggests that S727 most likely plays a negligible role in regulating the degree of kinase and phosphatase activities that govern the magnitude and duration of pY-STAT3. Notably, despite the equivalency of pY-STAT3 in infected $\mathrm{WT}$ and $S t a t 3^{\mathrm{SA} / \mathrm{SA}}$ mice, the latter infected mice display impaired gastric STAT3 target gene expression comparable to that of infected WT mice; this scenario supports the notion that during Helicobacter-induced gastric disease, pS727 is required for the maximal transcriptional capacity of STAT3 and predominates over pY705 as a regulator of the transcriptional capacity of STAT3. Among the STAT3 genes that were attenuated, TLR2 is a functionally important mediator not only for its ability to promote Helicobacterdependent inflammatory responses but also for its capacity to promote gastric tumorigenesis. ${ }^{37,44,45}$ Another key STAT3-regulated gene encodes IL-11 that has previously been shown to drive gastric tumorigenesis. ${ }^{21,37}$ Indeed, here we extend the role of IL-11 to also promoting $H$. felis-mediated gastric pathology. The comparable rescue in H. felis-induced gastric pathology in mice deficient in either IL-11R or pS-STAT3 implies that IL-11 signaling and STAT3 serine phosphorylation converge onto a final 
common pathway, or represent serial steps of the same pathway critical for the host response to $H$. felis infection.

The $H$. felis infection model reproduces the strong induction of inflammatory mediators observed in human $H$. pylori-infected tissues, including tumor necrosis factor- $\alpha$, interferon- $\gamma$, IL-1 $\beta$, CXCL1/KC, and CXCL2/macrophage inflammatory protein- $2 \alpha{ }^{46}$ Here, the up-regulated mRNA expression of these proinflammatory mediators was significantly attenuated in infected Stat $3^{\mathrm{SA} / \mathrm{SA}}$ mice, revealing a core role by which this neoplastic predisposing gastric inflammation is, at some point, dependent on STAT3 serine phosphorylation. In addition to inflammation, the host response to $H$. pylori infection involves the expansion of the proliferative epithelial zone in the gastric mucosa, a niche rich in progenitor and stem cells. ${ }^{47}$ In this regard, the gastric corpus stem cell marker CD44, which has been shown to be up-regulated in a STAT3-dependent manner in response to $H$. felis infection, plays a key role in $H$. pylori-induced epithelial cell proliferation. ${ }^{5,48}$ In infected Stat $3^{\text {SA/SA }}$ mice, the proliferative potential of the gastric corpus mucosa was greatly attenuated, and coincided with reduced expression of CD44 along with other representative STAT3-regulated proproliferative genes. ${ }^{49}$ Although these findings further support the notion that the Helicobacter-mediated transcriptional up-regulation of STAT3 target genes is dependent on pS727, the mechanistic basis by which pS-STAT3 can influence the proliferation (and self-renewal) of the stem/ progenitor cell compartment during Helicobacter-induced pathology remains unknown and thus warrants further investigation. In this respect, an epithelial intrinsic role for STAT3 activation in gastric tumorigenesis has been previously defined $^{21}$ and is supported by the recent demonstration that the conditional ablation of STAT3 in the gastric epithelium of mice suppresses proliferation, inflammation, and IM after long-term $H$. felis infection, which phenocopies the reduced gastric pathology of infected Stat3 ${ }^{\mathrm{SA} / \mathrm{SA}}$ mice. ${ }^{5}$ Although these observations lead us to propose that the pathogenic role of STAT3 in response to Helicobacter infection is largely dependent on epithelial intrinsic pS727, a potential role for pS-STAT3 in the immune compartment should not be excluded. Indeed, considering that $H$. pylo$r i-$ mediated gastric inflammation is characterized by the recruitment and accumulation of $\mathrm{CD}^{+} \mathrm{T}$ lymphocytes, including T helper (Th)1, Th17, and Th2 subsets for which STAT3 has a known regulatory role, ${ }^{3}$ it will be of interest to define the requirement, if any, for pS-STAT3 in such immune cell populations during Helicobacter infection.

In conclusion, we found that in response to chronic $H$. felis infection, pS727 plays a central role in maximizing the STAT3 transcriptional output of gene networks that promote pre-neoplastic gastric inflammation, mucosal hyperplasia, and IM. Furthermore, constitutive STAT3 serine phosphorylation in the gastric corpus mucosal epithelium (mouse, human) did not significantly change in expression in the pathologic setting of chronic Helicobacter infection. Conversely, STAT3 tyrosine phosphorylation exhibits a more binary expression pattern, whereby disease-free gastric mucosa displays a paucity of pY-STAT3 expression; pYSTAT3 expression levels are pronounced upon Helicobacter infection. It is thus tempting to propose that in the gastric mucosa, serine phosphorylation functions as a rheostat to allow cells to tune the magnitude and specificity of the STAT3 transcriptional program, which affords epithelial cells versatility in response to varying biological stimuli. In this regard, in Helicobacter-induced gastric disease, IL-11 is up-regulated and engages JAK-bound gp130 receptor complexes to induce pY-STAT3, which then facilitates STAT3 nuclear translocation and DNA binding affinity; this action thus licenses STAT3 with a broad transcriptional capacity. Upon entering the nucleus, basal (constitutive) pS-STAT3 is essential to augment the transcriptional induction of STAT3 target genes. Importantly, the current study now sets the stage to define the kinases that phosphorylate S727 on STAT3, as well as identify pSSTAT3 interacting partners, which collectively will provide new therapeutic opportunities that may be used in addition to antibiotic eradication of $H$. pylori to prevent disease progression.

\section{Author Contributions}

B.J.J. conceived and designed the study; J.J.B., L.M., K.D., R.L.F., and B.J.J. developed the methodology; J.J.B., M.I.S., R.D., A.C.W., A.J.W., K.D., V.D., L.M., and P.S.B. acquired the data; A.D. and W.S. provided samples; J.J.B., P.S.B., and B.J.J. analyzed and interpreted the data; J.J.B., D.J.G., R.L.F., and B.J.J. wrote, reviewed, and/or revised the manuscript; D.J.G. and B.J.J. supervised the study; B.J.J. is the guarantor of this work and, as such, had full access to all of the data in the study and takes responsibility for the integrity of the data and the accuracy of the data analysis.

\section{Supplemental Data}

Supplemental material for this article can be found at http://doi.org/10.1016/j.ajpath.2020.01.021.

\section{References}

1. Moss SF: The clinical evidence linking Helicobacter pylori to gastric cancer. Cell Mol Gastroenterol Hepatol 2016, 3:183-191

2. Correa P, Piazuelo MB: The gastric precancerous cascade. J Dig Dis 2012, 13:2-9

3. Jones SA, Jenkins BJ: Recent insights into targeting the IL-6 cytokine family in inflammatory diseases and cancer. Nat Rev Immunol 2018, 18:773-789

4. Bronte-Tinkew DM, Terebiznik M, Franco A, Ang M, Ahn D Mimuro H, Sasakawa C, Ropeleski MJ, Peek RM Jr, Jones NL: Helicobacter pylori cytotoxin-associated gene A activates the signal transducer and activator of transcription 3 pathway in vitro and in vivo [Erratum appeared in Cancer Res. 2013, 73:4170]. Cancer Res 2009, 69:632-639 
5. Ishii Y, Shibata W, Sugimori M, Kaneta Y, Kanno M, Sato T, Sue S, Kameta E, Kaneko H, Irie K, Sasaki T, Kondo M, Maeda S: Activation of signal transduction and activator of transcription 3 signaling contributes to Helicobacter-associated gastric epithelial proliferation and inflammation. Gastroenterol Res Pract 2018, 2018: 9050715

6. Zhao J, Dong Y, Kang W, Go MY, Tong JH, Ng EK, Chiu PW, Cheng AS, To KF, Sung JJ, Yu J: Helicobacter pylori-induced STAT3 activation and signalling network in gastric cancer. Oncoscience 2014, 1:468-475

7. Ericksen RE, Rose S, Westphalen CB, Shibata W, Muthupalani S, Tailor Y, Friedman RA, Han W, Fox JG, Ferrante AW Jr, Wang TC: Obesity accelerates Helicobacter felis-induced gastric carcinogenesis by enhancing immature myeloid cell trafficking and TH17 response. Gut 2014, 63:385-394

8. Lee IO, Kim JH, Choi YJ, Pillinger MH, Kim SY, Blaser MJ, Lee YC: Helicobacter pylori CagA phosphorylation status determines the gp130-activated SHP2/ERK and JAK/STAT signal transduction pathways in gastric epithelial cells. J Biol Chem 2010, 285: $16042-16050$

9. Piao JY, Lee HG, Kim SJ, Kim DH, Han HJ, Ngo HK, Park SA, Woo JH, Lee JS, Na HK, Cha YN, Surh YJ: Helicobacter pylori activates IL-6-STAT3 signaling in human gastric cancer cells: potential roles for reactive oxygen species. Helicobacter 2016, 21: $405-416$

10. Guanizo AC, Fernando CD, Garama DJ, Gough DJ: STAT3: a multifaceted oncoprotein. Growth Factors 2018, 36:1-14

11. Wen Z, Zhong Z, Darnell JE Jr: Maximal activation of transcription by Stat1 and Stat3 requires both tyrosine and serine phosphorylation. Cell 1995, 82:241-250

12. Zhang X, Blenis J, Li HC, Schindler C, Chen-Kiang S: Requirement of serine phosphorylation for formation of STAT-promoter complexes. Science 1995, 267:1990-1994

13. Shen Y, Schlessinger K, Zhu X, Meffre E, Quimby F, Levy DE, Darnell JE Jr: Essential role of STAT3 in postnatal survival and growth revealed by mice lacking STAT3 serine 727 phosphorylation. Mol Cell Biol 2004, 24:407-419

14. Zouein FA, Zgheib C, Hamza S, Fuseler JW, Hall JE, Soljancic A, Lopez-Ruiz A, Kurdi M, Booz GW: Role of STAT3 in angiotensin IIinduced hypertension and cardiac remodeling revealed by mice lacking STAT3 serine 727 phosphorylation. Hypertens Res 2013, 36: 496-503

15. Gough D, Corlett A, Schlessinger K, Wegrzyn J, Larner AC, Levy DE: Mitochondrial STAT3 supports Ras-dependent oncogenic transformation. Science 2009, 324:1713-1716

16. Wegrzyn J, Potla R, Chwae YJ, Sepuri NB, Zhang Q, Koeck T, Derecka M, Szczepanek K, Szelag M, Gornicka A, Moh A, Moghaddas S, Chen Q, Bobbili S, Cichy J, Dulak J, Baker DP, Wolfman A, Stuehr D, Hassan MO, Fu XY, Avadhani N, Drake JI, Fawcett P, Lesnefsky EJ, Larner AC: Function of mitochondrial Stat3 in cellular respiration. Science 2009, 323:793-797

17. Gough DJ, Marie IJ, Lobry C, Aifantis I, Levy DE: STAT3 supports experimental K-RasG12D-induced murine myeloproliferative neoplasms dependent on serine phosphorylation. Blood 2014, 124: $2252-2261$

18. Garama DJ, White C, Balic JJ, Gough DJ: Mitochondrial STAT3: powering up a potent factor. Cytokine 2016, 87:20-25

19. Wang DQ, Ding XP, Yin S, Mao YD: Role of the IL-11/STAT3 signaling pathway in human chronic atrophic gastritis and gastric cancer. Genet Mol Res 2016, 15:gmr7358

20. Sabry D, Abdelaleem OO, Hefzy EM, Ibrahim AA, Ahmed TI, Hassan EA, Abdel-Hameed ND, Khalil MAF: Interplay between Helicobacter pylori infection, interleukin-11, and leukemia inhibitory factor in gastric cancer among Egyptian patients. J Interferon Cytokine Res 2018, 38:517-525

21. Ernst M, Najdovska M, Grail D, Lundgren-May T, Buchert M, Tye H, Matthews VB, Armes J, Bhathal PS, Hughes NR,
Marcusson EG, Karras JG, Na S, Sedgwick JD, Hertzog PJ, Jenkins BJ: STAT3 and STAT1 mediate IL-11-dependent and inflammation-associated gastric tumourigenesis in gp130 receptor mutant mice. J Clin Invest 2008, 118:1727-1738

22. Ellmark P, Ingvarsson J, Carlsson A, Lundin BS, Wingren C, Borrebaeck CA: Identification of protein expression signatures associated with Helicobacter pylori infection and gastric adenocarcinoma using recombinant antibody microarrays. Mol Cell Proteomics 2006, 5:1638-1646

23. Dixon MF, Genta RM, Yardley JH, Correa P: Classification and grading of gastritis. The updated Sydney System. International Workshop on the Histopathology of Gastritis, Houston 1994. Am J Surg Pathol 1996, 20:1161-1181

24. Kennedy CL, Najdovska M, Jones GW, McLeod L, Hughes NR, Allison C, Ooi CH, Tan P, Ferrero RL, Jones SA, Dev A, Sievert W, Bhathal PS, Jenkins BJ: The molecular pathogenesis of STAT3driven gastric tumourigenesis in mice is independent of IL-17. J Pathol 2011, 225:255-264

25. Lawson AJ, Elviss NC, Owen RJ: Real-time PCR detection and frequency of $16 \mathrm{~S}$ rDNA mutations associated with resistance and reduced susceptibility to tetracycline in Helicobacter pylori from England and Wales. J Antimicrob Chemother 2005, 56:282-286

26. Nandurkar HH, Robb L, Tarlinton D, Barnett L, Köntgen F, Begley CG: Adult mice with targeted mutation of the interleukin-11 receptor (IL11Ra) display normal hematopoiesis. Blood 1997, 90: $2148-2159$

27. Lee A, Fox JG, Otto G, Murphy J: A small animal model of human Helicobacter pylori active chronic gastritis. Gastroenterology 1990, 99:1315-1323

28. Ferrero RL, Wilson JE, Sutton P: Mouse models of Helicobacterinduced gastric cancer: use of cocarcinogens. Methods Mol Biol 2012, 921:157-173

29. Velin D, Favre L, Bernasconi E, Bachmann D, Pythoud C, Saiji E, Bouzourene H, Michetti P: Interleukin-17 is a critical mediator of vaccine-induced reduction of Helicobacter infection in the mouse model. Gastroenterology 2009, 136:2237-2246.e1

30. Zhang S, Moss SF: Rodent models of Helicobacter infection, inflammation, and disease. Methods Mol Biol 2012, 921:89-98

31. Cai X, Carlson J, Stoicov C, Li H, Wang TC, Houghton J: Helicobacter felis eradication restores normal architecture and inhibits gastric cancer progression in C57BL/6 mice. Gastroenterology 2005, 128:1937-1952

32. Roth KA, Kapadia SB, Martin SM, Lorenz RG: Cellular immune responses are essential for the development of Helicobacter felisassociated gastric pathology. J Immunol 1999, 163:1490-1497

33. Mohammadi M, Redline R, Nedrud J, Czinn S: Role of the host in pathogenesis of Helicobacter-associated gastritis: H. felis infection of inbred and congenic mouse strains. Infect Immun 1996, 64:238-245

34. Calcagno DQ, Leal MF, Assumpcao PP, Smith MA, Burbano RR: MYC and gastric adenocarcinoma carcinogenesis. World J Gastroenterol 2008, 14:5962-5968

35. Mayer B, Jauch KW, Günthert U, Figdor CG, Schildberg FW, Funke I, Johnson JP: De-novo expression of CD44 and survival in gastric cancer. Lancet 1993, 342:1019-1022

36. Takano Y, Kato Y, Masuda M, Ohshima Y, Okayasu I: Cyclin D2, but not cyclin D1, overexpression closely correlates with gastric cancer progression and prognosis. J Pathol 1999, 189:194-200

37. Tye H, Kennedy CL, Najdovska M, McLeod L, McCormack W, Hughes N, Dev A, Sievert W, Ooi CH, Ishikawa TO, Oshima H, Bhathal PS, Parker AE, Oshima M, Tan P, Jenkins BJ: STAT3-driven upregulation of TLR2 promotes gastric tumorigenesis independent of tumor inflammation. Cancer Cell 2012, 22:466-478

38. Gollob JA, Schnipper C, Murphy EA, Ritz J, Frank DA: The functional synergy between IL-12 and IL-2 involves p38 mitogenactivated protein kinase and is associated with the augmentation of STAT serine phosphorylation. J Immunol 1999, 162: $4472-4481$ 
39. Jain N, Zhang T, Kee WH, Li W, Cao X: Protein kinase C delta associates with and phosphorylates Stat3 in an interleukin-6dependent manner. J Biol Chem 1999, 274:24392-24400

40. Lim CP, Cao X: Serine phosphorylation and negative regulation of Stat3 by JNK. J Biol Chem 1999, 274:31055-31061

41. Shi X, Zhang H, Paddon H, Lee G, Cao X, Pelech S: Phosphorylation of STAT3 serine-727 by cyclin-dependent kinase 1 is critical for nocodazole-induced mitotic arrest. Biochemistry 2006, 45: $5857-5867$

42. Waitkus MS, Chandrasekharan UM, Willard B, Tee TL, Hsieh JK, Przybycin CG, Rini BI, Dicorleto PE: Signal integration and gene induction by a functionally distinct STAT3 phosphoform. Mol Cell Biol 2014, 34:1800-1811

43. Decker T, Kovarik P: Serine phosphorylation of STATs. Oncogene 2000, 19:2628-2637

44. Smith SM: Role of Toll-like receptors in Helicobacter pylori infection and immunity. World J Gastrointest Pathophysiol 2014 $5: 133-146$
45. Mandell L, Moran AP, Cocchiarella A, Houghton J, Taylor N, Fox JG, Wang TC, Kurt-Jones EA: Intact gram-negative Helicobacter pylori, Helicobacter felis, and Helicobacter hepaticus bacteria activate innate immunity via toll-like receptor 2 but not toll-like receptor 4 . Infect Immun 2004, 72:6446-6454

46. Lindholm C, Quiding-Järbrink M, Lönroth $H$, Hamlet A, Svennerholm AM: Local cytokine response in Helicobacter pyloriinfected subjects. Infect Immun 1998, 66:5964-5971

47. Vries RG, Huch M, Clevers H: Stem cells and cancer of the stomach and intestine. Mol Oncol 2010, 4:373-384

48. Bertaux-Skeirik N, Feng R, Schumacher MA, Li J, Mahe MM Engevik AC, Javier JE, Peek RM Jr, Ottemann K, Orian-Rousseau V, Boivin GP, Helmrath MA, Zavros Y: CD44 plays a functional role in Helicobacter pylori-induced epithelial cell proliferation. PLoS Pathog 2015, 11:e1004663

49. Snyder M, Huang XY, Zhang JJ: Identification of novel direct Stat3 target genes for control of growth and differentiation. J Biol Chem 2008, 283:3791-3798 